\title{
RECONSTRUCTION OF FRACTURE SURFACES ON BORNITE
}

\author{
SARAH L. HARMER ${ }^{\S}$ \\ Department of Earth Sciences, University of Western Ontario, London, Ontario N6A 5B7, Canada \\ ALLEN R. PRATT ${ }^{g}$ \\ CANMET Mining and Mineral Sciences Laboratories, 555 Booth Street, Ottawa, Ontario K1A 0G1, Canada \\ H. WAYNE NESBITT and MichaEl E. FLEET \\ Department of Earth Sciences, University of Western Ontario, London, Ontario N6A 5B7, Canada
}

\begin{abstract}
Synchrotron-radiation X-ray Photoelectron Spectroscopy (SRXPS) and conventional X-ray Photoelectron Spectroscopy (XPS) have been used to study a pristine fracture-surface of bornite $\left(\mathrm{Cu}_{5} \mathrm{FeS}_{4}\right)$. Comparisons of these high-resolution spectra reveal, for the first time, four distinct contributions to the $\mathrm{S} 2 p$ spectra. The main symmetric peak of the $\mathrm{S} 2 p$ spectra for bornite is located at about $163.51 \mathrm{eV}$ and is derived from bulk $\mathrm{S}$ atoms. The broad nature of the bulk contribution, in comparison to other $3 d$ transition-metal sulfides such as chalcopyrite, is consistent with the presence of eight crystallographically distinct $\mathrm{S}$ sites within the structure, these sites being energetically as well as structurally distinct. A second peak located at $160.1 \mathrm{eV}$ is attributed to a surface monomeric species $\left(\mathrm{S}^{2-}\right)$ of lower coordination. The presence of a second broad surface-contribution at $162.1 \mathrm{eV}$ likely represents surface polymeric species $\left(\mathrm{S}_{n}{ }^{2-}\right)$. The presence of surface sulfur polymers indicates the stabilization of the bornite surface upon fracture through formation of S-S bonds. These data suggest that surface polymers form where polar surfaces are exposed during conchoidal fracture. A high binding-energy tail was observed at about $163 \mathrm{eV}$ and extends to about $166 \mathrm{eV}$, the origin of which is uncertain. Conventional XPS Cu $2 p$ and $\mathrm{Fe} 2 p$ spectra collected from a pristine fracture-surface of bornite reveal a $\mathrm{Cu}^{1+}$ peak centered at about $932.2 \mathrm{eV}$ and a high-spin $\mathrm{Fe}^{3+}$ peak centered at $708 \mathrm{eV}$.
\end{abstract}

Keywords: X-ray photoelectron spectroscopy, bornite, sulfides, iron, copper, surface speciation.

\section{SOMMAIRE}

Nous avons utilisé la spectroscopie photo-électronique des rayons X en rayonnement synchrotron (SRXPS) et la spectroscopie photo-électronique des rayons $\mathrm{X}$ conventionnelle (XPS) pour étudier une surface fracturée très fraiche de la bornite $\left(\mathrm{Cu}_{5} \mathrm{FeS} \mathrm{S}_{4}\right)$. A la suite de comparaisons de ces spectres à résolution élevée, nous démontrons pour la première fois quatre contributions distinctes au spectre de l'atome $\mathrm{S} 2 p$. Le pic symétrique principal du spectre de $\mathrm{S} 2 p$ de la bornite est situé à environ 163.51 $\mathrm{eV}$, et il est dérivé de la masse globale des atomes de $\mathrm{S}$. La nature généralisée de cette contribution globale, par rapport aux autres sulfures de métaux de transition $3 d$ tels la chalcopyrite, concorde avec la présence de huit sites $\mathrm{S}$ cristallographiquement distincts dans la structure, tous ces sites étant aussi énergétiquement et structuralement distincts. Un second pic situé à 160.1 $\mathrm{eV}$ est attribuable à une espèce de surface monomérique $\left(\mathrm{S}^{2-}\right)$ ayant une coordinence plus faible. La présence d'une seconde contribution de surface généralisée à $162.1 \mathrm{eV}$ représenterait l'espèce polymérique de surface $\left(\mathrm{S}_{n}{ }^{2-}\right)$. La présence de polymères de soufre de surface indique la stabilisation de la surface de la bornite suite à une fracture par la formation de liaisons S-S. D'après ces données, les polymères de surface semblent se former où les surfaces polaires deviennent exposées lors du développement d'une surface conchoïdale. Un prolongement du spectre indiquant une énergie de liaison élevée est présente à environ $163 \mathrm{eV}$ et atteint environ $166 \mathrm{eV}$; son origine demeure incertaine. Les spectres conventionnels XPS de $\mathrm{Cu} 2 p$ et de Fe $2 p$ prélevés à partir d'une surface de fracture très fraiche révèlent un pic de l'atome $\mathrm{Cu}^{1+}$ centré à environ $932.2 \mathrm{eV}$ et un pic dû au $\mathrm{Fe}^{3+}$ à l'état de spin élevé centré à 708 eV.

(Traduit par la Rédaction)

Mots-clés: spectroscopie photo-électronique des rayons X, bornite, sulfures, fer, cuivre, spéciation de la surface.

$\S \quad$ Present address: CSIRO Manufacturing and Infrastructure Technology, PO Box 4, Woodville, SA 5011, Australia. E-mail address: sarah.harmer@csiro.au

I E-mail address: apratt@nrcan.gc.ca 


\section{INTRODUCTION}

Bornite $\left(\mathrm{Cu}_{5} \mathrm{FeS}_{4}\right)$, a ternary semiconducting mineral commonly found in massive sulfide deposits, is an important source of copper. Sulfide minerals such as bornite, covellite $(\mathrm{CuS})$, chalcocite $\left(\mathrm{Cu}_{2} \mathrm{~S}\right)$ and chalcopyrite $\left(\mathrm{CuFeS}_{2}\right)$ are extracted from their ores by flotation. The efficiency of their recovery is determined entirely by their surface properties. The preparation of ores for industrial beneficiation processes generally involves grinding to specific size-fractions. The result is the production of fractured and cleaved surfaces. Understanding the consequences of exposing these fracture surfaces to air and solutions is important in improving the efficiency of these industrial processes. As the initial reactivity of bornite with air and fluids will depend on the nature of its surface, the key to understanding the reaction mechanisms is to determine its reactivity via the study of surface chemistry and structures formed upon fracture. To this end, a massive sample of in-vacuum fractured bornite has been analyzed by synchrotron-radiation X-ray photoelectron spectroscopy (SRXPS) and conventional X-ray photoelectron spectroscopy (XPS).

\section{Previous Studies}

Previous studies of bornite have shown rapid oxidation in response to exposure to air, with concomitant change in color from bronze to a purple bluish color (Vaughan et al. 1987, Buckley \& Woods 1983, Losch $\&$ Monhemius 1976). XPS analysis of the oxidation of bornite in air has revealed a surface layer of iron oxyhydroxide and hydrated iron oxide covering a subsurface of $\mathrm{Cu}_{5} \mathrm{~S}_{4}$ composition (Buckley \& Woods 1983, Vaughan et al. 1987). However, little is known of the pristine surfaces on bornite and how these iron oxyhydroxides are formed.

To determine the reactivity of bornite, one must first understand the surface states formed upon fracture. The surface properties of cleaved surfaces of binary semiconductors having the sphalerite structure extensively studied over the past few decades (Hinkel et al. 1988, Eastman et al. 1980, Leiro et al. 1998, Nesbitt et al. 1998, 2000, 2001, 2002, Uhlig et al. 2001, Biegelsen et al. 1990a, b, Pashley et al. 1988, Kaxiras et al. 1986, Nakada \& Osaka 1991). However, few studies of ternary semiconductors have been performed. Bornite does not have perfect cleavage. Studies of the surface states and reactivities of different crystallographic planes thus cannot be investigated separately on a natural sample of bornite. Instead a fracture surface of bornite has been investigated.

The nature of the fracture surface provides exposure of multiple crystallographic planes, each with surface signals (Harmer et al. 2004). These surface signals are most conveniently studied using SRXPS and XPS techniques.

\section{Crystal Structure}

Bornite is a ternary chalcogenide with a direct energy band-gap $\left(E_{\mathrm{g}}\right)$ of approximately $1 \mathrm{eV}$ (Jaegermann \& Tributsch 1988). It is found as polycrystalline (massive) samples in sulfide deposits, along with other $\mathrm{Cu}-$ and $\mathrm{Fe}$-bearing minerals. There are three temperature-dependent polymorphs of bornite, referred to as the low-, intermediate- and high-temperature forms. The low and intermediate forms are superstructures of the cubic ( $a 5.5 \AA$ ) high-temperature bornite. They exhibit increasing order of vacancies with decreasing temperature (Koto \& Morimoto 1975). The low-temperature bornite $(<443 \mathrm{~K})$, as studied herein, has an orthorhombic unit-cell with $a 10.95, b 21.862, c 10.95$ $\AA$ (Koto \& Morimoto 1975). There are an average of eighty $\mathrm{Cu}$, sixteen $\mathrm{Fe}$ and sixty-four $\mathrm{S}$ atoms per unit cell.

Bornite structures are based on a cubic closestpacked array of $\mathrm{S}$ atoms, with $\mathrm{Cu}$ and $\mathrm{Fe}$ atoms in tetrahedral interstices. Koto \& Morimoto (1975) recognized that the superstructure of low bornite is built of two unit cubes of the closest-packed structure, one of composition $(\mathrm{Cu}, \mathrm{Fe})_{4} \mathrm{~S}_{4}$ having the structure of sphalerite and the other of composition $(\mathrm{Cu}, \mathrm{Fe})_{8} \mathrm{~S}_{4}$ having the antifluorite structure. Sphalerite- and antifluorite-type cubes alternate along the crystallographic axes forming a mosaic pattern (Fig. 1). There are 12 crystallographically distinct metal positions per unit cell and eight sulfur positions. In the antifluorite-type cubes, the metal atoms are in a distorted tetrahedral coordination with $\mathrm{S}$, giving either three short and one slightly long metal-S bonds or two short and two slightly longer ones. The shortest metal-metal distance is $2.755 \AA$. In contrast, the four metal atoms of the sphalerite-type cube are markedly displaced from the centers of the tetrahedra toward triangular coordination with the sulfur atom; the $M(10)$ site is actually in threefold coordination. The shortest metal-metal distance is $3.045 \AA$; $\mathrm{Cu}$ and $\mathrm{Fe}$ atoms were not distinguished in the Koto \& Morimoto (1975) structure. The structure of low bornite represents an approach to complete order of metal atoms and vacancies within the array of $\mathrm{S}$ atoms; the vacancies are ordered in the sphalerite-type cubes. The dimensions of each sphalerite- or antifluorite-type cubes corresponds, of course, to the unit cell of high bornite. The atom positions determined by Koto \& Morimoto (1975) were used to generate a model of the low bornite structure using ATOMS (Shape Software, 2004). Bonds were generated up to $2.9 \AA$ in length; the resulting structure shows sulfur atoms in both 5- and 6 -fold coordination.

\section{INSTRUMENTAL PARAMETERS}

Samples were cut from a massive sample of bornite from Transvaal, South Africa. Quantitative electronmicroprobe analysis of the sample was performed at 


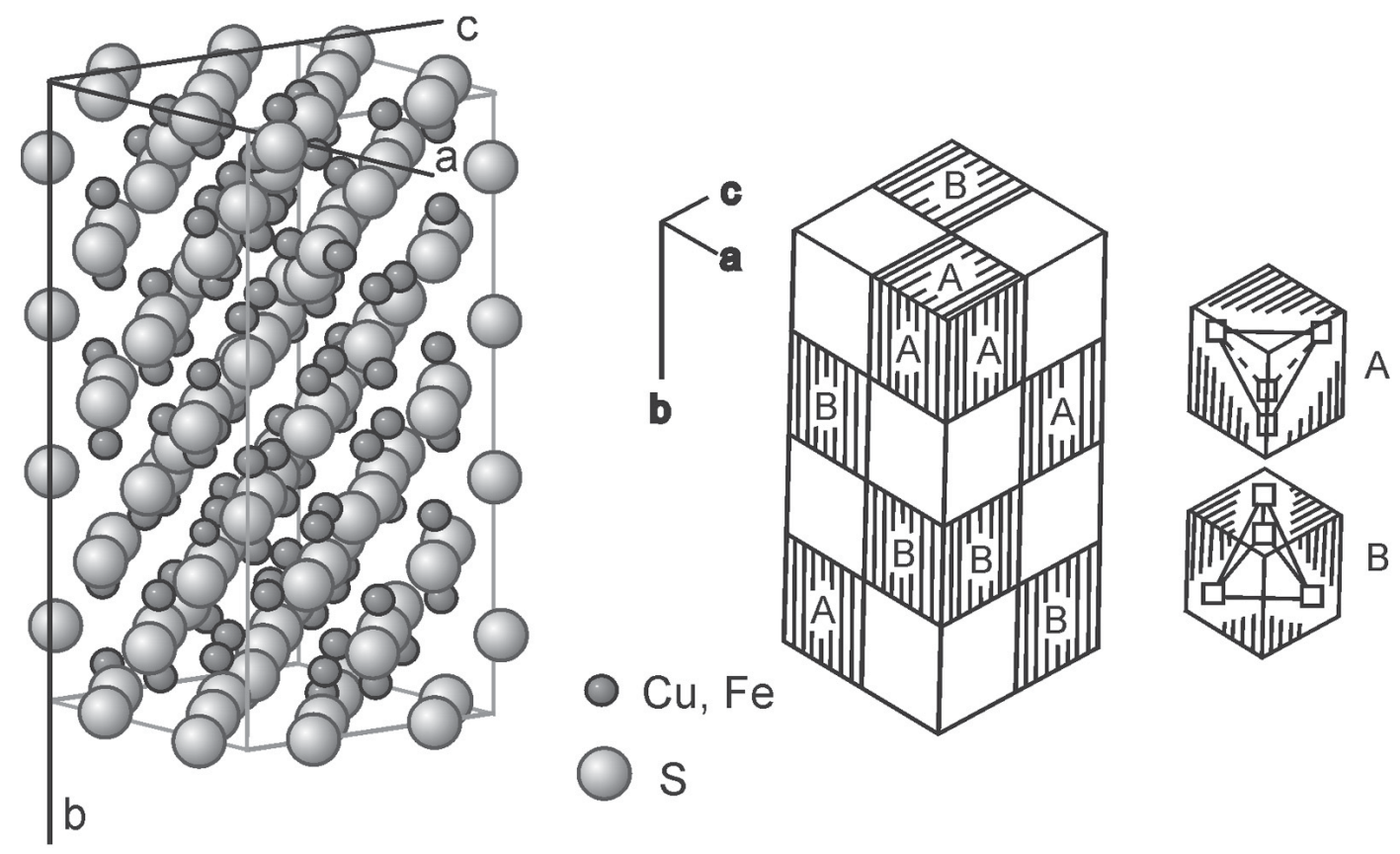

FIG. 1. The unit cell of bornite. There are antifluorite-type cubes with all metal sites filled (white) and sphalerite-type cubes with four vacancies (hatched) in the bornite superstructure (Koto \& Morimoto 1975). The sphalerite cubes have two different orientations owing to the arrangement of the metal vacancies in the sulfur tetrahedra (as shown by hatched cubes A and B).

CANMET by wavelength-dispersion spectrometry using a JEOL 8900 electron microprobe operated at $20 \mathrm{kV}$ and $20 \mathrm{nA}$. The electron-microprobe analysis revealed small inclusions of chalcopyrite and minor amounts of quartz. The sample showed good homogeneity, with trace amounts of Ag. The stoichiometry is close to $\mathrm{Cu}_{4.89} \mathrm{Fe}_{1.02} \mathrm{~S}_{4.09}$. Powder XRD analysis confirmed that the sample consists of low-temperature, orthorhombic bornite.

SRXPS studies were conducted using the HERMON beamline with a Scienta analyzer at the University of Wisconsin Synchrotron Radiation Center (Nesbitt et al. 2000). A photon energy of $225 \mathrm{eV}$ was used to study the $\mathrm{S} 2 p$ line for optimal surface sensitivity. The data were collected at $8 \times 10^{-10}$ Torr and $20 \mathrm{~K}$. Conventional XPS data were collected using a Kratos Axis Ultra fitted with a monochromated $\mathrm{AlK} \alpha$ source (1487 $\mathrm{eV}$ ) operating at $15 \mathrm{kV}$ and $14 \mathrm{~mA}$, with a spot size of $300 \mu \mathrm{m}$. The detector is positioned at $90^{\circ}$ to the sample surface, enabling analysis up to a depth of $10 \mathrm{~nm}$. The samples were fractured under vacuum at $1 \times 10^{-7}$ Torr prior to being transferred to the analytical chamber for analysis at $1 \times 10^{-9}$ Torr and $180 \mathrm{~K}$. Survey scans were collected using a pass energy of $160 \mathrm{eV}$ and a step size of $0.7 \mathrm{eV}$ to ensure purity of the sample and cleanliness of the fracture. High-resolution spectra were collected at $10 \mathrm{eV}$ pass energy using a step size of $0.025 \mathrm{eV}$. The spectrometer was standardized to $\mathrm{Au} 4 f_{7 / 2}$ at $84.0 \mathrm{eV}$ and calibrated using $\mathrm{Cu} 2 p_{3 / 2}$ at $936.7 \mathrm{eV}$. The pristine sample did not display charging.

\section{SPeCtRAl PROPERTIES AND FItS}

X-ray photoelectron spectroscopy (XPS) is a common technique for understanding the electronic properties of solids and gases. Oxidation state, bonding partners, electronic-spin state, and now more than before, coordination number can be determined (Nesbitt 2002, Briggs \& Seah 1990, Hüfner 1996, Barr 1994). Consequently, XPS has become a powerful technique for studying the near-surface properties of materials.

The $\mathrm{S} 2 p$ spectra shown in Figure 2 were fitted using spin-orbit splitting parameters with the $\mathrm{S} 2 p_{3 / 2}$ and $\mathrm{S}$ $2 p_{1 / 2}$ peaks separated by $1.19 \mathrm{eV}$, and with relative peak-areas of $2: 1$. The S $2 p$ spectra were fitted using peak shapes of $50 \%$ Gaussian, $50 \%$ Lorentzian $(\mathrm{G} / \mathrm{L})$ character. The $\mathrm{G} / \mathrm{L} \%$ of the fitted $\mathrm{Cu} 2 p_{3 / 2}$ peak was varied to provide the best fit to the leading edge of the $\mathrm{Cu} 2 p_{3 / 2}$ line. The $\mathrm{Cu} 2 p_{3 / 2}$ spectra shown in Figure 3 were fitted using peaks shapes of $20 \%$ Gaussian. Shirley backgrounds were used to fit all spectra (Shirley 1972). No oxygen was detected at the surface of the vacuumfractured sample. 

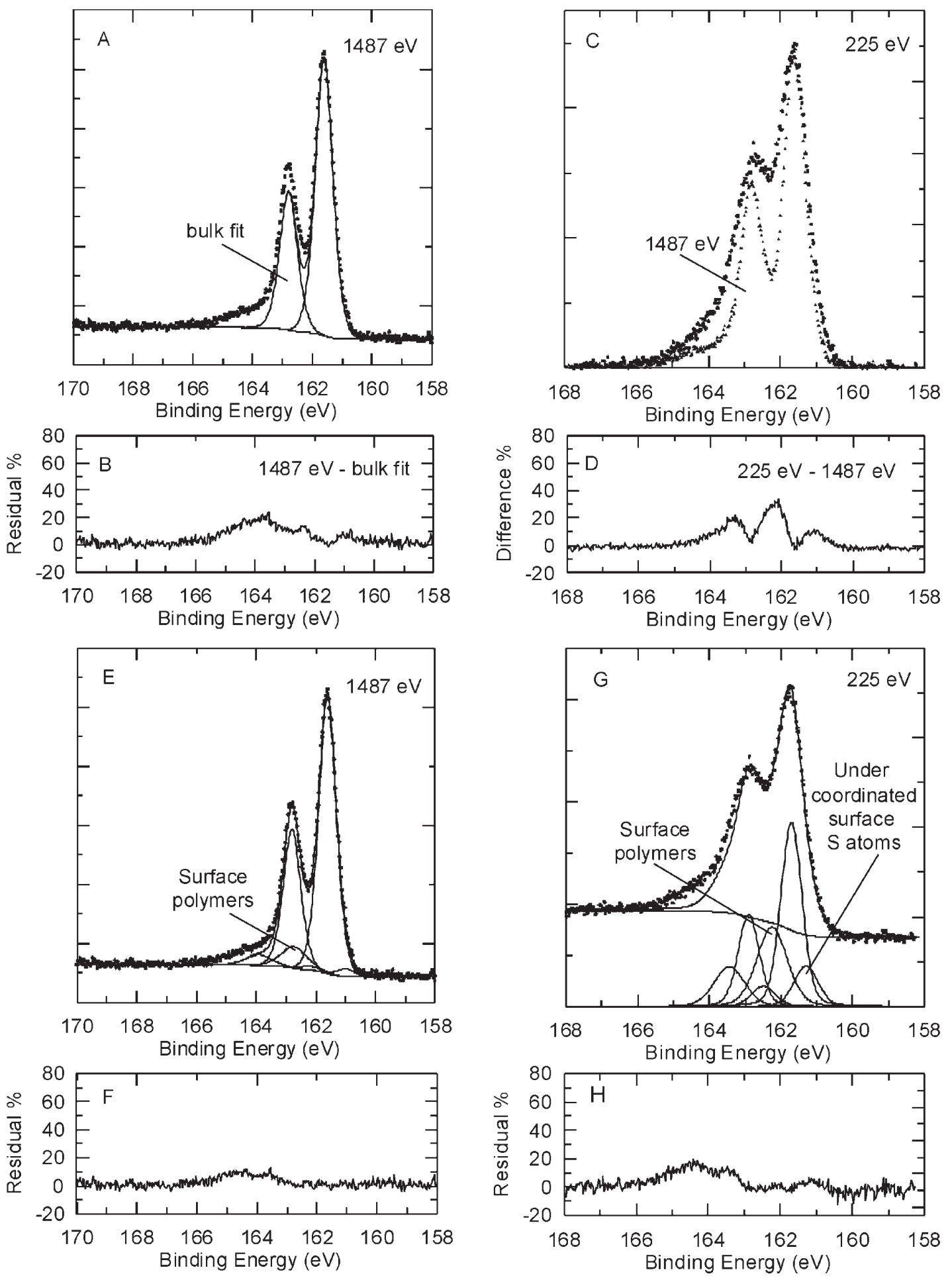
The kinetic energy of the $\mathrm{S} 2 p$ photoelectrons is about $1326 \mathrm{eV}$ when using an $\mathrm{Al} K \alpha$ source at $1487 \mathrm{eV}$ (work function not considered). These high-kineticenergy photoelectrons usually traverse approximately 15 atomic layers before attenuation, packing density not considered (Briggs \& Seah 1990, Seah \& Dench 1979), so that the bulk S $2 p$ signal contributes $90-95 \%$ of the total intensity of sulfur, whereas the surface signal contributes $5-10 \%$ of the of the total sulfur intensity (Tanuma et al. 1991, Briggs \& Seah 1990, Seah \& Dench 1979). Consequently, the most intense contribution to the conventional spectrum must be the $\mathrm{S} 2 p$ signal of bulk, fully coordinated sulfur atoms.

Using an energy of $225 \mathrm{eV}$ incident photons (Fig. 2C) yields S $2 p$ photoelectrons of about $90 \mathrm{eV}$. These low-kinetic-energy photoelectrons usually traverse one to four monolayers before attenuation (Briggs \& Seah 1990, Seah \& Dench 1979). This spectrum is therefore highly surface-sensitive. Although the bulk signal should be the most intense peak in the spectrum, S surface states should contribute about $45 \%$ of the total signal (Nesbitt et al. 2000, Schaufuss et al. 1998a, b, Uhlig et al. 2001).

The kinetic energy of the $\mathrm{Cu} 2 p$ and Fe $2 p$ photoelectrons is about $555 \mathrm{eV}$ and $779 \mathrm{eV}$ if using an $\mathrm{Al} K \alpha$ source at $1487 \mathrm{eV}$ (work function not considered). Photoelectrons of these kinetic energies usually traverse approximately five and six monolayers before attenuation (Briggs \& Seah 1990, Seah \& Dench 1979), so that the bulk $\mathrm{Cu} 2 p$ and $\mathrm{Fe} 2 p$ signals contribute about $70 \%$ of the total $\mathrm{Cu}$ and $\mathrm{Fe}$ intensity, whereas the surface signal (1-2 atomic layers) contributes about $30 \%$ of the of the total $\mathrm{Fe}$ and $\mathrm{Cu}$ intensity (Tanuma et al. 1991, Briggs \& Seah 1990, Seah \& Dench 1979).

FIG. 2. A) Conventional XPS S $2 p$ spectrum collected from a fractured surface of a sample of massive bornite at $1487 \mathrm{eV}$ photon energy. The figure shows a fit to the $\mathrm{S} 2 p$ spectrum that includes a Shirley background and a doublet representing bulk $\mathrm{S}$ atoms. B) Residual of the fit shown in Figure 2A. C) Comparison of the SRXPS data collected from a fractured surface of massive bornite at $225 \mathrm{eV}$ with the conventional XPS S $2 p$ spectrum collected at 1487 $\mathrm{eV}$. D) Residuals of the $225 \mathrm{eV}$ SRXPS spectrum minus the $1487 \mathrm{eV}$ conventional XPS S $2 p$ spectrum, indicating the energy position of the surface $\mathrm{S}$ species. E) Fit to the conventional XPS S $2 p$ spectrum to include two additional doublets, a low-binding-energy doublet representing surface monomers and a higher-binding-energy doublet representing surface polymers. F) The residual of the fit shown in Figure 2E. G) A fit to the SRXPS S $2 p$ spectrum to include two additional doublets, a low-binding-energy doublet representing surface monomers and a higherbinding-energy doublet representing surface polymers. H) The residual of the fit shown in Figure 2G.

\section{INTERPRETATION OF S $2 P$ SPECTRA}

\section{Bulk signals}

The XPS S $2 p$ spectra (Fig. 2A) include two spinorbit split peaks, the $\mathrm{S} 2 p_{3 / 2}$ and the $2 p_{1 / 2}$. These are consistent with the two peaks of the XPS S $2 p$ spectrum (Fig. 2A). A doublet with a FWHM of $0.7 \mathrm{eV}$ has been added to the spectrum at $161.59 \mathrm{eV}$ (Fig. 2A, Table 1). This binding energy (BE) is somewhat higher than that of the S $2 p_{3 / 2}$ line of chalcopyrite found at $161.33 \mathrm{eV}$ (Harmer et al. 2004). The small increase in BE is due to an increase in the coordination number of $\mathrm{S}$ and a larger proportion of $\mathrm{Cu}$ in bornite, as compared to chalcopyrite. The increase in coordination number changes the crystal-field strength surrounding the $S$ atoms. In this case, a change in coordination from 4-fold coordination as in chalcopyrite to 5- and 6-fold coordination in bornite should decrease the electron density surrounding the $\mathrm{S}$ atoms in bornite. The electrons are less readily removed from the atom, thereby increasing their BE. In addition, the greater proportion of $\mathrm{Cu}$ than $\mathrm{Fe}$ in bornite as compared to chalcopyrite may explain the higher $\mathrm{S} 2 p$ BE. As $\mathrm{Cu}$ has a greater electronegativity than $\mathrm{Fe}$, the $\mathrm{Cu}$ atom has a greater density of electrons, thereby decreasing the electron density of surrounding $\mathrm{S}$ atoms. The fitted doublet contributes $88 \%$ of the total sulfur signal, and has therefore been attributed to fully coordinated bulk $\mathrm{S}$ atoms. The bimodal nature of the residual spectrum (Fig. 2B) indicates the presence two surface signals that, if summed, contribute about $12 \%$ of the total S intensity. In addition to the surface signals, there is a high-binding-energy-loss feature centered at $163.5 \mathrm{eV}$.

The SRXPS spectrum of vacuum-fractured bornite collected using a photon energy of $225 \mathrm{eV}$, compared to the XPS spectrum, is shown in Figure 2C. One of the most remarkable features of these spectra is the broad nature of the $2 p_{3 / 2}$ and $2 p_{1 / 2}$ peaks, in comparison with those of other sulfides. Chalcopyrite, pyrite, marcasite

TABLE 1. SRXPS AND XPS PEAK PARAMETERS AND CHEMICAL STATES OF S OBTAINED FROM FRACTURED SURFACES ON BORNITE

\begin{tabular}{|c|c|c|c|c|}
\hline Species & $\begin{array}{c}\text { Binding } \\
\text { Energy } \\
(\mathrm{eV})\end{array}$ & $\begin{array}{c}\text { Peak } \\
\text { widths } \\
\text { (FWHM) }\end{array}$ & $\begin{array}{c}\text { Proportion } \\
\text { of } \mathrm{S} \text { species } \\
\text { (at.\%) }\end{array}$ & Comments \\
\hline \multicolumn{5}{|c|}{ XPS $1487 \mathrm{eV}$} \\
\hline $\mathrm{S}_{\text {monamer }}$ & 160.98 & 0.72 & 2.4 & Surface monomer \\
\hline $\mathrm{S}_{\text {lulk }}$ & 161.60 & 0.70 & 88.0 & Fully coordinated bulk $S$ \\
\hline $\mathrm{S}_{\text {polymer }}$ & 162.81 & 1.00 & 9.6 & Surface polymer \\
\hline \multicolumn{5}{|c|}{ SRXPS $225 \mathrm{eV}$} \\
\hline $\mathrm{S}_{\text {mononnor }}$ & 161.51 & 0.79 & 13.5 & Surface monomer \\
\hline$S_{\text {bulk }}$ & 161.10 & 0.70 & 53.3 & Fully coordinated bulk $S$ \\
\hline$S_{\text {polyner }}$ & 162.05 & 1.00 & 33.1 & Surface polymer \\
\hline
\end{tabular}



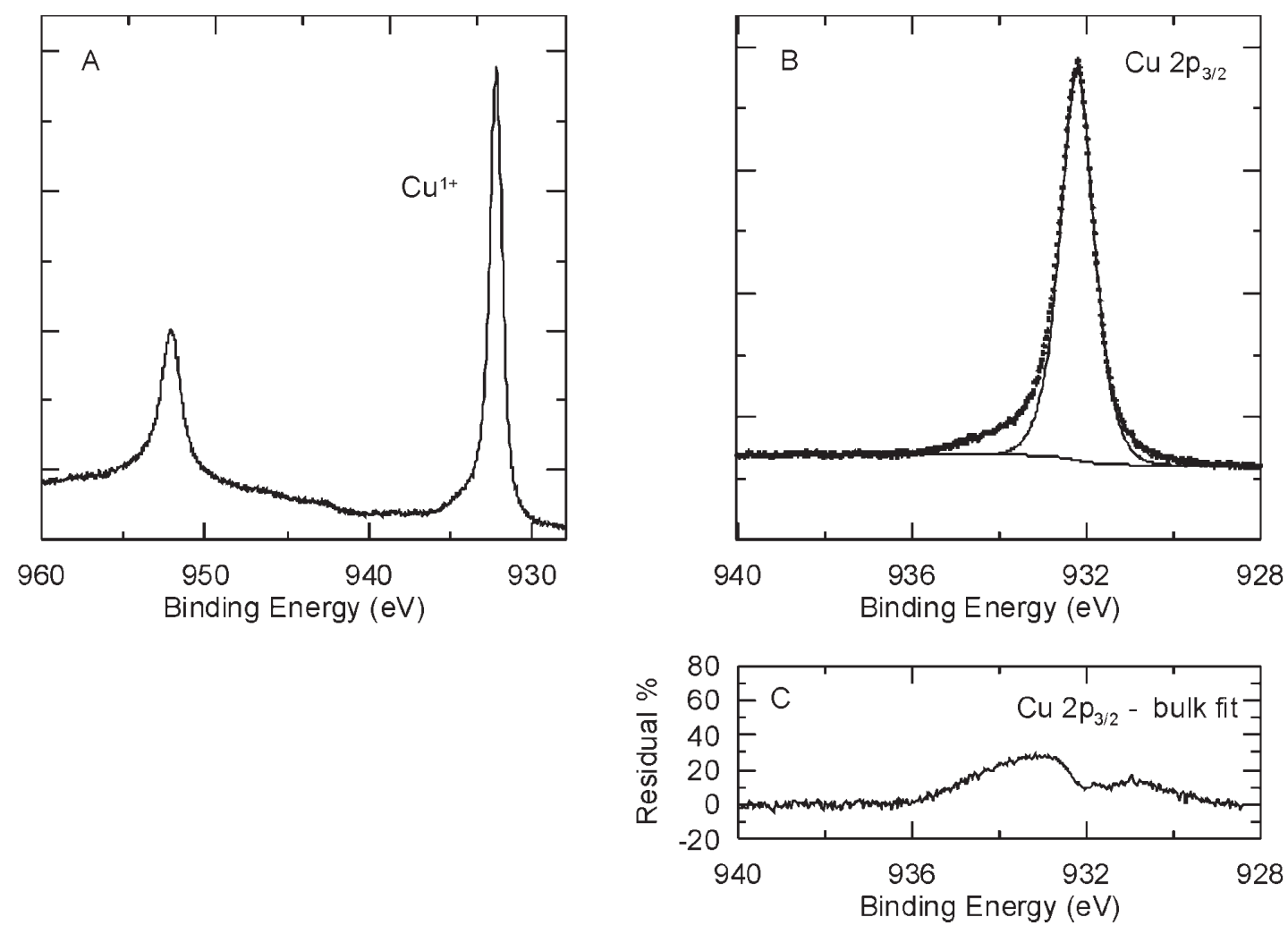

FIG. 3. A) Conventional XPS Cu $2 p$ spectrum collected from an in-vacuum fracture surface of bornite at $1487 \mathrm{eV}$ photon energy. B) Conventional XPS Cu $2 p_{3 / 2}$ spectrum as shown in Figure 3A. The figure shows a fit to the $\mathrm{Cu} 2 p_{3 / 2}$ spectrum that includes a Shirley background and a single peak representing bulk $\mathrm{Cu}$ atoms. C) The residual of the fit shown in Figure 3B.

and arsenopyrite display FWHM values in the order of $0.46,0.57,0.55$ and $0.6 \mathrm{eV}$ (Harmer et al. 2004, Harmer \& Nesbitt 2004). The 1487 eV S $2 p$ bornite spectrum exhibits a much shallower minimum between the $\mathrm{S} 2 p_{3 / 2}$ and $\mathrm{S} 2 p_{1 / 2}$ than that observed for other sulfides. In addition, the $225 \mathrm{eV}$ spectrum does not show obvious inflections or shoulders due to surface species. This broadening may be explained by the differences in crystal structure between bornite and other sulfides such as chalcopyrite. Where chalcopyrite has S tetrahedrally coordinated to $\mathrm{Cu}$ and $\mathrm{Fe}$ atoms, bornite has $\mathrm{S}$ coordinated to $\mathrm{Cu}$ and $\mathrm{Fe}$ in both 5- fold and 6-fold coordinations, at eight different structural sites. Changes in the electron density surrounding the $\mathrm{S}$ atoms at each of the eight sites and the two coordinations result in several different XPS signals. The change in electron density in the 5-fold coordinated S compared to 6-fold coordination causes a shift in binding energies resulting in broadening of the bulk and surface peaks. The energy differences, however, must be small and are not resolved in the SRXPS and XPS spectra. Consequently, one doublet has been used to represent both 5-fold and 6-fold coordinated bulk S atoms.

From theory, the bulk signals should represent $60-65 \%$ of the total SRXPS S $2 p$ spectrum and $85-90 \%$ of the conventional XPS S $2 p$ spectrum (Seah \& Dench 1979). The majority of the SRXPS spectrum arises from the bulk. Consequently, the most intense peak centered at $161.59 \mathrm{eV}$ has been identified as the $\mathrm{S} 2 p_{3 / 2}$ peak representing fully coordinated bulk $\mathrm{S}$ atoms in both 5-fold and 6-fold coordination (Figs. 2A, C).

\section{SURFACE CONTRIBUTIONS AND THEIR ORIGINS}

\section{Spectral fit}

Owing to spectral broadening, identification of the surface contributions in the S $2 p$ spectra of bornite is not as straightforward as in other sulfides (Harmer $e t$ al. 2004, Harmer \& Nesbitt 2004, Nesbitt et al. 1998, 2000, Schaufuss et al. 1998a, Uhlig et al. 2001). Thus, an alternative approach to the spectral fitting is required. 
To reveal the approximate positions of the surface states, the difference between the surface-sensitive $225 \mathrm{eV}$ SRXPS spectrum and the bulk-sensitive 1487 $\mathrm{eV}$ conventional XPS spectrum has been plotted in Figure 2D. The intensity of the surface contributions are reduced by about $5-10 \%$, and the high-binding-energy tail resulting from the $1487 \mathrm{eV}$ spectrum is removed. The bimodal nature of the difference spectrum indicates that there are two surface states present.

Recent SRXPS and conventional XPS spectra of chalcopyrite reveal that the S $2 p$ signals are of similar resolution (Harmer et al. 2004). It is, therefore, reasonable to assume that the FWHM of the bulk S $2 p$ signal observed using conventional XPS can be used as the bulk signal for the $225 \mathrm{eV}$ SRXPS spectrum. The bulk-sensitive S $2 p$ conventional XPS signal has been subtracted from the surface-sensitive SRXPS spectrum, with the difference shown in Figure 2D. Three distinct maxima are visible in the difference spectrum, with the central maximum the most intense. These imply two distinct spin-orbit split contributions, with the $\mathrm{S}$ $2 p_{1 / 2}$ peak of one superimposed on the $\mathrm{S} 2 p_{3 / 2}$ peak of the other, to yield the intense central maximum. Note also that the high binding-energy tail is absent from the difference spectrum.

The difference spectrum indicates the presence of two surface contributions to the bornite $\mathrm{S} 2 p$ spectra, just as observed for chalcopyrite. The two contributions are included in the fit shown in Figures $2 \mathrm{E}$ and $2 \mathrm{~F}$. The lower-binding-energy surface signal has been identified as a surface core-level shift contribution, and the second higher-binding-energy contribution has been interpreted as a surface dimer, as for chalcopyrite it (Harmer et al. 2004).

There may be an additional spin-orbit split doublet at $163 \mathrm{eV}$; the region between 164 and $166 \mathrm{eV}$, however, is more likely explained by an energy-loss feature, as shown by Figures $2 \mathrm{E}$ and $2 \mathrm{~F}$. The lack of any intensity due to the high-binding-energy tail in the difference spectrum (Fig. 2D) indicates that the tail is the same intensity in the bulk $1487 \mathrm{eV}$ spectrum and the $225 \mathrm{eV}$ surface-sensitive spectrum. It is, therefore, apparent that the tail is not a result of surface species. A similar feature was observed in the SRXPS and conventional XPS S $2 p$ spectra of chalcopyrite, pyrite, marcasite, arsenopyrite and pyrrhotite (Harmer et al. 2004, Harmer \& Nesbitt 2004, Nesbitt et al. 2000, 2001, Schaufuss et al. 2000). Although the origin of this tail is not certain, it may be due to a ligand-to-metal transfer mechanism (i.e., S $3 p$ to $\mathrm{Fe} 3 d$ ), as concluded by Fujisawa et al. (1994) for chalcopyrite.

\section{Origin of the surface monomer}

Surface monomeric species were first observed by Eastman et al. (1980) when studying the (110) surface of GaAs. The As $3 d$ spectrum of GaAs includes two contributions, one representing As atoms of the bulk phase and the second, a low-binding-energy peak, referred to as a surface core-level shifted peak, resulting from surface As atoms. The origin of surface corelevel shifts in semiconducting compounds is related to electronegativity. In covalent compounds containing elements of different electronegativity, stabilization of the fracture surface may be achieved by redistribution of electrons on surface atoms (Harrison 1979). Atoms of greater electronegativity (typically ligands such as S or As) are likely to acquire greater electron-density, and the metal atoms, diminished electron-density compared to their respective counterparts in the bulk of the compound. The increase in electron density surrounding the ligand results in a shift to lower binding-energy (Mönch 1995, Gibson \& LaFemina 1996, Harmer et al. 2004). Consequently, similar core-level shifted peaks should be observed on the high-binding-energy side of the $\mathrm{Cu} 2 p$ and $\mathrm{Fe} 2 p$ signals, representing surface cations with lower electron-density than the fully coordinated bulk cations. Surface core-level shifts have been observed in a variety of semiconducting compounds, including InSb (Hinkel et al. 1988), GaSb (Eastman et al. 1980), $\mathrm{PbS}$ (Leiro et al. 1998), $\mathrm{FeS}_{2}$ (pyrite and marcasite, Nesbitt et al. 1998, 2000, Uhlig et al. 2001), $\mathrm{Fe}_{1-x} \mathrm{~S}$ (pyrrhotite), NiS (millerite, Nesbitt et al. 2001) and $\mathrm{CuFeS}_{2}$ (Harmer et al. 2004).

\section{Origin of the surface polymers}

The second surface signal is located at a BE slightly greater than that from the bulk (monomeric) $\mathrm{S}$ atoms. The higher binding-energy indicates that electron density surrounding these sulfur atoms has decreased in comparison to the bulk $\mathrm{S}$ atoms and is in the range expected for surface dimers (about $162 \mathrm{eV}$ ). The concentration of the surface core-level shifted peak, and these additional, presumably surface dimers, represent $47 \%$ of the total SRXPS sulfur signal (Table 1), as predicted by the universal curve (Briggs \& Seah 1990, Seah \& Dench 1979). The broad nature of the contribution may suggest the presence of longer oligomer chains, possibly trimers or tetramers. Surface polymeric species have been observed on a variety of mineral surfaces including chalcopyrite (Harmer et al. 2004) and löllingite (Uhlig et al. 2001). The implication is that the sulfur-rich surface has undergone reconstruction.

\section{INTERPRETATION OF THE METAL 2P Lines}

\section{The $\mathrm{Cu} 2 p_{3 / 2}$ bulk signal}

The $\mathrm{Cu} 2 p_{3 / 2}$ spectrum collected from a pristine $\mathrm{Cu}_{5} \mathrm{FeS}_{4}$ fracture surface using conventional XPS (Fig. 3A) includes a strong singlet peak, but no shakeup satellite contribution between about 940 and $945 \mathrm{eV}$, indicating that the oxidation state of $\mathrm{Cu}$ in bornite is $1+$ (McIntyre \& Cook 1975, Nakai et al. 1977, Deroubaix $\&$ Marcus 1992). The $\mathrm{Cu} 2 p_{3 / 2}$ spectrum is distinctly 
asymmetric, displaying one intense peak located at about $932.2 \mathrm{eV}$, and a weak high-binding-energy tail that extends to about $936 \mathrm{eV}$ (Fig. 3B).

A single symmetric peak was fitted to the $\mathrm{Cu} 2 p_{3 / 2}$ spectrum at $932.18 \mathrm{eV}$. The $\mathrm{BE}$ of the $\mathrm{Cu} 2 p$ peak is similar to that in other copper and copper-iron sulfides (McIntyre \& Cook 1975, Nakai et al. 1977, Deroubaix \& Marcus 1992, Harmer et al. 2004). The peak's FWHM and G/L contribution was adjusted to fit the low-binding-energy side of the peak. The fitted peak was found to have a FWHM of $0.9 \mathrm{eV}$ and a $20 \%$ Gaussian (80\% Lorentzian). The peak's intensity was adjusted to contribute $70 \%$ of the total $\mathrm{Cu} 2 p_{3 / 2}$ signal, as expected from theory (Seah \& Dench 1979) (Fig. 3B). The bulk signal represents $\mathrm{Cu}^{1+}$ bonded in both tetrahedral and triangular coordination with sulfur.

The low-binding-energy side of the peak does not provide a good fit to the spectrum, as seen by the positive residuals. The origin of this contribution is not known at this stage. However, there are three possible explanations for this phenomenon: beam damage (Frost et al. 1972), chemisorption of hydrogen (Barr 1994), an incorrect $\mathrm{G} / \mathrm{L}$ function or an unidentified energygain process.

X-rays have previously been shown to cause photoreduction of surface species (Frost et al. 1972). However, as this is a well-known fact, time-resolved spectra were taken to ensure that this is not an issue. Chemisorption of hydrogen also has been shown to alter spectra (Barr 1994). However, in this case, less than 5\% $\mathrm{C}-\mathrm{H}$ and no detectable $\mathrm{H}_{2} \mathrm{O}$ or $\mathrm{OH}$ were observed on

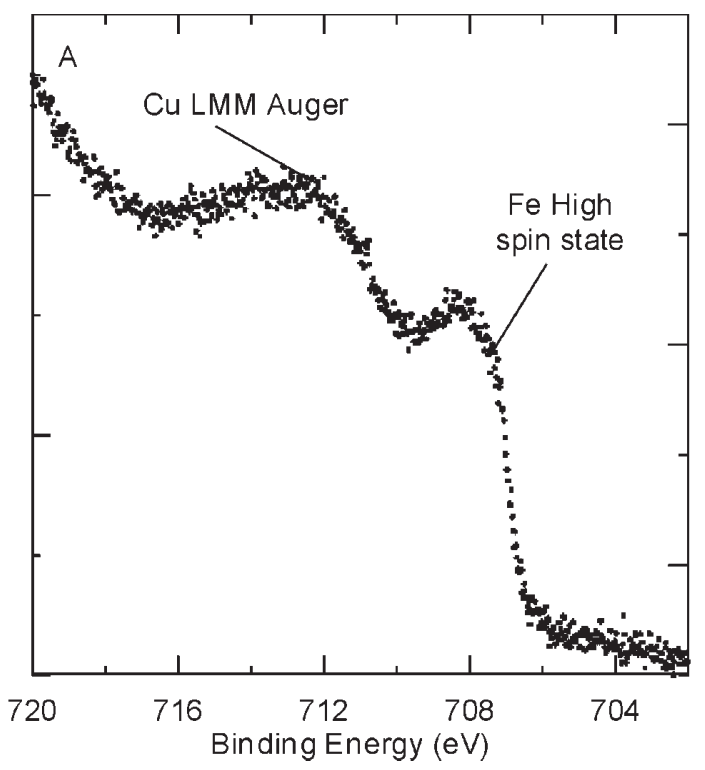

the surface after the analysis period. The most likely origin of this phenomenon is an incorrect G:L function for fitting the XPS spectra or an unknown energy-gain process.

\section{Cu $2 p_{3 / 2}$ surface signal}

The residuals plot, shown in Figure 3C, was obtained by adjusting the bulk peak to represent $70 \%$ of the total $\mathrm{Cu} 2 p_{3 / 2}$ signal and calculating the remainder of the two signals. The difference spectrum indicates a broad contribution at a higher binding-energy than the bulk phase. This contribution has been identified as a surface chemical state. With diminished electron-density on the surface metal atoms, the remaining electrons are more strongly bound to the metal nucleus, resulting in a surface core-level shifted peak, as observed on the low-BE side of the S $2 p$ peak. Similar high-bindingenergy tails have been observed for $\mathrm{Fe} 2 p$ spectra of pyrite, marcasite, arsenopyrite and löllingite (Nesbitt et al. 2000). They have been interpreted as $\mathrm{Fe}^{2+}$ and $\mathrm{Fe}^{3+}$ surface states formed as a result of fracture. Further SRXPS experimentation is needed to determine the origin of the high-binding-energy contribution(s).

\section{Fe $2 p_{3 / 2}$ signal}

The Fe $2 p$ spectrum obtained from the in-vacuum fractured bornite is shown in Figure 4A. The spectrum reveals a broad peak centered at $708 \mathrm{eV}$; it has been identified as the Fe $2 p_{3 / 2}$ signal. In addition, there is a

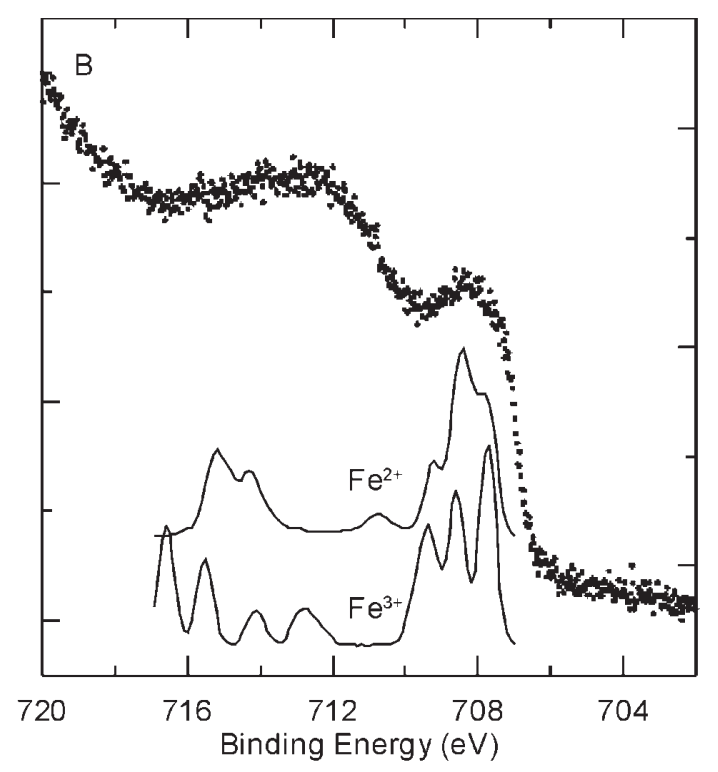

FIG. 4. Conventional XPS Fe $2 p_{3 / 2}$ spectrum collected from an in-vacuum fracture surface of bornite at $1487 \mathrm{eV}$ photon energy in comparison with the theoretical multiplet structures of high-spin $\mathrm{Fe}^{2+}$ and $\mathrm{Fe}^{3+}$, as calculated by Gupta \& Sen (1975). 
second broad peak centered at about $712 \mathrm{eV}$. The latter peak has been identified as a $\mathrm{Cu}$ LMM Auger line. Additionally, the Auger contribution overlaps with the region where surface core-level shifted peaks and other surface species are expected. Consequently, deconvolution of the spectrum is ambiguous.

Authors of Mössbauer studies of bornite have concluded that the oxidation state of $\mathrm{Fe}$ in bornite is high-spin $\mathrm{Fe}^{3+}$ above $140 \mathrm{~K}$ (Jagadeesh et al. 1981, Vaughan et al. 1987). The XPS Fe $2 p$ spectrum is, therefore, expected to exhibit multiplet splitting. Multiplet splitting arises in $3 d$ transition metals that have unpaired electrons in valence band ( $3 d$ orbitals). Upon emission of a photoelectron from a core level, the angular momentum of the partially filled core-shell interacts with the angular momentum of the unpaired valence-electrons, causing a multiplet set of peaks (Gupta \& Sen 1975, Briggs \& Seah 1990, Hüfner 1996, Nesbitt 2002). The broad nature of the $\mathrm{Fe} 2 p_{3 / 2}$ signal substantiates the Mössbauer studies performed by Jagadeesh et al. (1981).

The intensity of the "free ion" multiplet structure has been calculated by Gupta \& Sen (1975) for various transition metal ions. The suggested multiplet structure of $\mathrm{Fe}^{3+}$ has been shown to fit reasonably well for materials that contain $\mathrm{Fe}$ in octahedral coordination (McIntyre \& Zetaruk 1977, Nesbitt et al. 2000). The Fe $2 p_{3 / 2}$ spectrum of pristine bornite is compared with the multiplet structures of both high-spin $\mathrm{Fe}^{2+}$ and $\mathrm{Fe}^{3+}$, as calculated by Gupta $\&$ Sen, in Figure 4B. The second and third of the calculated $\mathrm{Fe}^{3+}$ multiples are too intense to provide a good fit to the spectrum, whereas the first multiplet of the calculated $\mathrm{Fe}^{2+}$ spectrum is too weak to provide a good fit to the leading edge of the $\mathrm{Fe} 2 p_{3 / 2}$ signal.

It is apparent from this study and from studies of chalcopyrite that the intensity of the multiplets does not provide a good fit to the spectrum for $\mathrm{Fe}$ in tetrahedral or triangular coordination. There are several possible reasons for these observations, such as crystal-field effects, satellite structures and surface states.

The Fe in bornite is in both trigonal and tetrahedral coordinations, and not present as a free ion, as used for the calculations of Gupta \& Sen (1975), who considered that crystal-field effects appear to play a significant role. Their calculations were much simpler when these effects were eliminated, however. They suggested that changes in the crystal field would lead to a significant redistribution of the intensity of some spectral lines. In addition, configurations other than that of the ground state may need to been taken into consideration to predict the observed satellite structure in the XPS spectra. Finally, surface states contribute up to $30 \%$ of the peak intensity when using a conventional $\mathrm{Al} K \alpha$ source. The surface states could, therefore, have a significant effect on peak shape. As the surface states for Fe $2 p$ spectra of bornite have not yet been observed owing to a lack of an appropriate SRXPS facility, it is not possible to deconvolute the spectra with certainty.
Thus at this stage, the Fe $2 p$ XPS spectra of bornite cannot be fitted, and the analysis of the spectra remains qualitative.

It may be noted, however, that the BE of tetrahedrally coordinated high-spin $\mathrm{Fe}^{3+}$ is not considerably higher than that of low-spin octahedrally coordinated $\mathrm{Fe}^{2+}$. A peak fitted along the leading edge of the $\mathrm{Fe}$ $2 p_{3 / 2}$ spectrum for pristine bornite is only $0.2 \mathrm{eV}$ higher than low-spin $\mathrm{Fe}^{2+}$ observed for $\mathrm{FeS}_{2}$ (pyrite), not the $1 \mathrm{eV}$ expected from such an increase in oxidation state (Harmer \& Nesbitt 2004). This observation may be caused by changes in the surrounding crystal-field. The local electron-density about tetrahedrally and trigonally coordinated $\mathrm{Fe}$ is greater than that of octahedrally coordinated Fe. The increase in electron density results in more readily removed electrons, and thus electrons of lower binding-energy. Consequently, the assignment of Fe oxidation states is ambiguous. It is apparent that significantly more research is needed to understand the multiplet structure of $3 d$ transition-metal compounds.

\section{Discussion}

\section{Fracture surfaces and reconstruction}

The fracture of a material involves breaking of bonds between surface atoms, resulting in the formation of high-energy dangling bonds at the fracture surface. The surface is then considered to have a high surface free-energy. The response of the surface to fracture is to minimize the surface free-energy via the elimination of these high-energy dangling bonds (Mönch 1995).

Surfaces that consist of an equal number of cations and anions are essentially charge-neutral in materials that have equal numbers of cations and anions. These surfaces are commonly referred to as autocompensated surfaces. No reconstructions are observed on these surfaces, but the surface atoms relax from their initial positions (Mönch 1995). Dangling bonds of anions are occupied, and those of cations are empty (i.e., the result is a shift in electron density to the more electronegative species). This is the lowest energy state for such a surface, and is indicated by a surface core-level shift in XPS spectra. Surface core-level shifts have been observed in a variety of covalent chalcogenides and other semiconductors, including InSb (Hinkel et al. 1988), GaSb (Eastman et al. 1980), PbS (Leiro et al. 1998), $\mathrm{FeS}_{2}$ (pyrite and marcasite, Nesbitt et al. 1998, 2000, Uhlig et al. 2001), $\mathrm{Fe}_{1-x} \mathrm{~S}$ (pyrrhotite), NiS (millerite, Nesbitt et al. 2001), $\mathrm{CuFeS}_{2}$ (Harmer et al. 2004) and have been associated with autocompensated surfaces. The bornite structure has few surfaces that contain both cations and anions, such as the (011) and the (110) planes. However, owing to the metal-excess nature of bornite, these surfaces are not charge-neutral. This fact helps to explain the lower concentration of surface core-level shifts at the surface of bornite, as compared to chalcopyrite (Harmer et al. 2004). 
Other atomic planes in bornite [e.g., (101), (001), (100), (010)] result in either metal-terminated or sulfur-terminated surfaces. These surfaces have highenergy dangling bonds and tend to reconstruct to lower the surface free-energy. Reconstructions have been observed in the form of surface dimers and longer oligomer chains of anions in a number of materials, including GaAs (Biegelsen et al. 1990a, b, Pashley et al. 1988, Kaxiras et al. 1986), InSb (Nakada \& Osaka 1991), $\mathrm{FeAs}_{2}$ (Nesbitt et al. 2002) and $\mathrm{CuFeS}_{2}$ (Harmer et al. 2004).

Cleavage along the (001), (100) or (010) planes results in rupture of two metal-S and two metal-metal bonds, whereas cleavage along the (111) and (101) planes results in the breakage of one bond per surface metal atom and either one or two bonds per surface $S$ atom. The $\mathrm{S}$ atoms at the fracture surface of bornite are, therefore, reduced to 3-, 4- and 5-fold coordinations, and the metal atoms are reduced to 2 - and 3 -fold coordinations. As a result of fracture, a highly complex polar, high-energy surface is created. The response of this surface to fracture is the formation of a slightly S-rich surface $\left(\mathrm{Cu}_{4.37} \mathrm{Fe}_{0.87} \mathrm{~S}_{4.76}\right)$ composed of $\mathrm{S}$ monomers and polymers (e.g., dimers). The presence of metal vacancies may further assist the formation of S polymers, as there are no intervening metal atoms to inhibit adjacent $\mathrm{S}$ atoms from tilting their bonds to form dimers.

\section{Implications on reactivity}

Fracture surfaces have a larger number of defects than do perfect cleavage surfaces. Fracture surfaces on bornite produce polar, high-energy surfaces, as indicated by the surface reconstruction to form $\mathrm{S}$ polymers. The reactivity of a surface increases with the concentration of dangling bonds at the surface, as they provide opportunities for adsorption of chemicals species such as $\mathrm{O}_{2}$ and $\mathrm{H}_{2} \mathrm{O}$. Furthermore, as suggested by Vaughan et al. (1987), Fe in three-fold coordination is not found in nature and is highly likely to be unstable in that form. Copper, on the other hand, is commonly found in 3-fold coordination. The $\mathrm{Fe}$ atoms with exposed dangling bonds at the bornite fracture-surface are more likely to be open to attack by oxidants such as $\mathrm{O}_{2}$ and $\mathrm{H}_{2} \mathrm{O}$. Copper is more chalcophile, and may tend form polysulfides, as oxidation studies by Buckley \& Woods (1983) and Vaughan et al. (1987) have shown.

\section{ACKNOWLEDGEMENTS}

The authors of this paper dedicate this article to their coauthor Mike Fleet and communicate their thanks and congratulations to him upon his retirement. We thank Mike for his endless support and enlightening conversations on transition-metal sulfides. May he be as successful in his retirement as in his long and distinguished career.
We thank Grant Henderson and Robert F. Martin for their valuable reviews and processing of this manuscript, Mike Bancroft for insightful conversations, Roberta Flemming for assistance with graphics, Tatiana Karamaneva for XRD analysis of the bornite sample, J.H.G. Laflamme at CANMET MMSC for EPMA, and Bill Skinner for assistance with SRXPS data collection. Experiments were conducted at Surface Science Western (SSW) and the Synchrotron Radiation Center (SRC). This work was supported by NSERC grants awarded to H.W. Nesbitt and M.E. Fleet, and a Synchrotron Steering Committee at Natural Resources Canada grant to A.R. Pratt.

\section{REFERENCES}

BARr, T.R. (1994): Modern ESCA - The Principles and Practices of X-ray Photoelectron Spectroscopy. CRC Press Inc., Boca Raton, Florida (318).

Biegelsen, D.K., Bringans, R.D., Northrup, J.E. \& SwartZ, L.E. (1990a): Reconstructions of GaAs (111) surfaces observed by scanning tunneling microscopy. Phys. Rev. Lett. 65, $452-457$.

$$
\text { \& }
$$
(1990b): Surface reconstructions of GaAs $(100)$ observed by scanning tunneling microscopy. Phys. Rev. B41, 5701-5710.

Briggs, D. \& Seah, M.P., eds. (1990): Practical Surface Analysis. 1. Auger and X-ray Photoelectron Spectroscopy. John Wiley \& Sons, New York, N.Y.

BuCKLEY, A.N. \& Woods, R. (1983): An X-ray photoelectron spectroscopic investigation of the tarnishing of bornite. Aust. J. Chem. 36, 1793-1804.

Deroubaix, G. \& Marcus, P. (1992): X-ray photoelectron spectroscopy analysis of copper and zinc oxides and sulphides. Surface and Interface Anal. 18, 39-46.

Eastman, D.E., Chiang, T.-C., Heimann, P. \& Himpsel, F.L. (1980): Surface core-level binding-energy shifts for GaAs(110) and GaSb(110). Phys. Rev. Lett. 45, 656-659.

Frost, D.C., Ishitani, A. \& McDowell, C.A. (1972): X-ray photoelectron spectroscopy of copper compounds. Mol. Phys. 24, 861- 877.

Fujisawa, M., Suga, S., Mizokawa, T., Fujimori, A. \& SATO, K. (1994): Electronic structures of $\mathrm{CuFeS}_{2}$ and $\mathrm{CuAl}_{0.9} \mathrm{Fe}_{0.1} \mathrm{~S}_{2}$ studied by electron and optical spectroscopies. Phys. Rev. B49, 7155-7163.

Gibson, A.S. \& LAFEmina, J.P. (1996): Structure of mineral surfaces. In Physics and Chemistry of Mineral Surfaces (P.V. Brady, ed.). CRC press, Boca Raton, Florida.

GuPTA, R.P. \& SEN, S.K. (1975): Calculation of multiplet structure of core $p$-vacancy levels II. Phys. Rev. B12, 15-19. 
HARMER, S.L. \& NESBITT, H.W (2004): Stabilization of pyrite $\left(\mathrm{FeS}_{2}\right)$, marcasite $\left(\mathrm{FeS}_{2}\right)$, arsenopyrite (FeAsS) and loellingite $\left(\mathrm{FeAs}_{2}\right)$ surfaces by polymerization and auto-redox reactions. Surf. Sci. 564, 38-52.

Pratt, A.R., Nesbitt, H.W. \& FleEt, M.E. (2004): Sulfur species at chalcopyrite $\left(\mathrm{CuFeS}_{2}\right)$ fracture surfaces. Am. Mineral. 89, 1026-1032.

HARRISON, W.A. (1979): Theory of polar semiconductor surfaces. J. Vac. Sci. Technol. 16, 1492-1496.

Hinkel, V., Sorba, L. \& HoRn, K. (1988): Surface core level shifts of clean and hydrogen covered InSb(110). Surf. Sci. 194, 597-614.

HüFNER, S. (1996): Photoelectron Spectroscopy Principles and Applications ( $2^{\text {nd }}$ ed.). Springer-Verlag, New York, N.Y.

JaEgermanN, W. \& TRIBUtsch, W. (1988): Interfacial properties of semiconducting transition metal chalcogenides. Progr. Surf. Sci. 29, 1-167.

Jagadeesh, M.S., Nagarathna, H.M., Montano, P.A. \& SeEHRA, M.S. (1981): Magnetic and Mössbauer studies of phase transitions and mixed valences in bornite $\left(\mathrm{Cu}_{4.5} \mathrm{Fe}_{1.2} \mathrm{~S}_{4.7}\right)$. Phys. Rev. B23, 2350-2356.

Kaxiras, E., Bar-Yam, Y., Joannopoulos, J.D. \& Pandey, K.C. (1986): Variable stoichiometry surface reconstructions: new models for GaAs $(\overline{111})(2 \times 2)$ and $(\sqrt{ } 19 \times$ V19). Phys. Rev. Lett. 57, 106-109.

Kото, K. \& MоRiмото, N. (1975): Superstructure investigation of bornite, $\mathrm{Cu}_{5} \mathrm{FeS}_{4}$, by the modified partial Patterson function. Acta Crystallogr. B31, 2268-2273.

Leiro, J.A., Laajalehto, K., Kartio, I. \& Heinonen, M.H. (1998): Surface core-level and phonon broadening in $\mathrm{PbS}$ (100). Surface Science 412-413, L918-L923.

Losch, W. \& Monhemius, A. (1976): An AES study of a copper-iron sulphide mineral. Surf. Sci. 60, 196-210.

McInTYRe, N.S. \& CoOK, M.G. (1975): X-ray photoelectron studies on some oxides and hydroxides of cobalt, nickel, and copper. Anal. Chem. 47, 2208-2213.

\& ZeTARUK, D.G. (1977): X-ray photoelectron spectroscopic studies of iron oxides. Anal. Chem. 49, 1521-1528.

MöNCH, W. (1995): Semiconductor Surfaces and Interfaces. Springer-Verlag, Berlin, Germany.

NAKADA, T. \& OsaKa, T. (1991): Sb trimer structure of the $\mathrm{InSb}(111) \mathrm{B}-(2 \times 2)$ surface as determined by transmission electron diffraction. Phys. Rev. Lett. 67, 2834-2837.

Nakai, I., Sugitani,Y. \& Nagashima, K. (1977): X-ray photoelectron spectroscopic study of copper minerals. J. Inorg. Nucl. Chem. 40, 789-791.
NeSBitT, H.W. (2002): Interpretation of X-ray photoelectron spectra with applications to mineralogy and geochemistry. In Synchrotron Radiation: Earth, Environmental and Material Sciences Applications (G.S. Henderson, D.R. Baker \& R. Raeside, eds.). Mineral. Assoc. Can., Short Course Vol. 30, 131-158.

Bancroft, G.M., Pratt, A.R. \& Scaini, M.J. (1998): Sulfur and iron surface states on fractured pyrite surfaces. Am. Mineral. 83, 1067-1076.

, Scaini, M., Höchst, H., Bancroft, G.M., Schaufuss, A.G. \& Szargan, R. (2000): Synchrotron XPS evidence for $\mathrm{Fe}^{2+} \mathrm{S}$ and $\mathrm{Fe}^{3+} \mathrm{S}$ surface species on pyrite fracture-surfaces, and their 3D electronic states. Am. Mineral. 85, 850-857.

Schaufuss, A.G., Scaini, M., Bancroft, G.M. \& SZARGAN, R. (2001): XPS measurement of fivefold and six-fold coordinated sulfur in pyrrhotites and evidence for millerite and pyrrhotite surface species. Am. Mineral. 86, 318-326.

Uhlig, I. \& SzARgan, R. (2002): Surface reconstruction and As-polymerization at fractured loellingite $\left(\mathrm{FeAs}_{2}\right)$ surfaces. Am. Mineral. 87, 1000-1004.

Pashley, M.D., Haberern, K.W., Friday, W., Woodal, J.M \& KIRCHNER, P.D. (1988): Structure of GaAs(001) $(2 \times 4)$ $-c(2$ (8) determined by scanning tunneling microscopy. Phys. Rev. Lett. 60, 2176-2179.

Schaufuss, A.G., Nesbitt, H.W., Kartio, I., LaAjalehto, K., BANCROFt, G.M. \& SZARGAN, R. (1998a): Reactivity of surface chemical states on fractured pyrite. Surf. Sci. 411, 321-328.

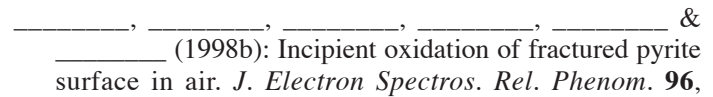
69-82.

Scaini, M.J., HoEchst, H., Bancroft, M.G. \& SZARGAN, R. (2000): Reactivity of surface sites on fractured arsenopyrite (FeAsS) toward oxygen. Am. Mineral. 85, 1754-1766.

SeAh, M.P. \& Dench, W.A. (1979): Quantitative electron spectroscopy of surfaces: a standard database for electron inelastic mean free paths in solids. Surf. Inter. Anal. 1, 2-11.

Shape Software, Atoms, version 5.1, (C) 2004.

SHIRLEY, D.A. (1972): High-resolution X-ray photoemission spectrum of the valence bands of gold. Phys. Rev. B5, 4709-4714.

Tanuma, S., Powell, C.J. \& Penn, D.R. (1991): Calculations of electron inelastic mean free paths. II. Data for 27 elements over the 50-2000 eV range. Surf. Inter. Anal. 17, 911-926. 
Uhlig, I., Szargan, R., Nesbitt, H.W. \& Laajalehto, K. Vaughan, D.J., Tossell, J.A. \& Stanley, C.J. (1987): The (2001): Surface states and reactivity of pyrite and marca- $\quad$ surface properties of bornite. Mineral. Mag. 51, 285-293. site. Appl. Surf. Sci. 179, 223-230.

Received August 31, 2004, revised manuscript accepted August 1, 2005. 